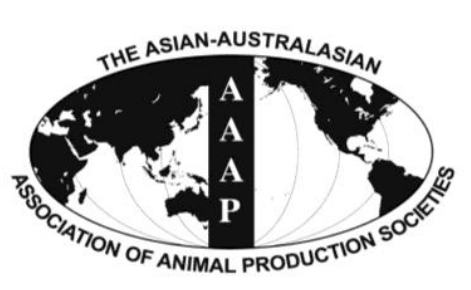

Open Access

Asian Australas. J. Anim. Sci.

Vol. 28, No. 2 : 273-279 February 2015

http://dx.doi.org/10.5713/ajas.14.0440

www.ajas.info

pISSN 1011-2367 elSSN 1976-5517

\title{
Interaction between Leptospiral Lipopolysaccharide and Toll-like Receptor 2 in Pig Fibroblast Cell Line, and Inhibitory Effect of Antibody against Leptospiral Lipopolysaccharide on Interaction
}

\author{
Yijie Guo ${ }^{1,2}$, Tomokazu Fukuda ${ }^{3}$, Shuichi Nakamura ${ }^{4}$, Lanlan Bai ${ }^{1}$, Jun Xu ${ }^{1}$, Kengo Kuroda ${ }^{1}$, \\ Rintaro Tomioka ${ }^{1}$, Hiroshi Yoneyama ${ }^{1}$, and Emiko Isogai ${ }^{1}{ }_{*}$ \\ ${ }^{1}$ Laboratories of Animal Microbiology, Graduate School of Agricultural Science, \\ Tohoku University, Sendai 981-8555, Japan
}

\begin{abstract}
Leptospiral lipopolysaccharide (L-LPS) has shown potency in activating toll-like receptor 2 (TLR2) in pig fibroblasts (PEFs_NCC1), and causes the expression of proinflammatory cytokines. However, the stimulation by L-LPS was weak eliciting the function of TLR2 sufficiently in pig innate immunity responses during Leptospira infection. In this study, the immune response of pig embryonic fibroblast cell line (PEFs_SV40) was investigated and was found to be the high immune response, thus TLR2 is the predominate receptor of L-LPS in pig cells. Further, we found a strategy using the antibody against L-LPS, to prevent L-LPS interaction with TLR2 in pig cells which could impact on immune activation. (Key Words: Antibody Against Leptospiral Lipopolysaccharide, Cytokines, Leptospiral Lipopolysaccharide, Pig Fibroblast Cell Line, Toll-like Receptor 2)
\end{abstract}

\section{INTRODUCTION}

Leptospirosis is a zoonotic disease caused by bacteria belongs to the genus Leptospira (Brenner et al., 1999). Approximately 200 different serovars of Leptospira interrogans have been identified which are the etiological agents of leptospirosis (Cerqueira and Picardeau, 2009). L. interrogans serovar Pomona, Grippotyphosa and Hebdomadis are considered as the most significant serovars for pig leptospirosis worldwide (Faine, 1994). The symptoms be found on infected pigs are not frequently

\footnotetext{
* Corresponding Author: Emiko Isogai. Tel: +81-022-717-8708, Fax: +81-022-717-8708, E-mail: emiko@ bios.tohoku.ac.jp

2 Department of Immunobiology and Pathogenic Biology, Medical School of Xi'an Jiaotong University, Xi'an 710061, China.

${ }^{3}$ Laboratory of Animal Breeding and Genetics, Agricultural Science, Tohoku University, Sendai 981-8555, Japan.

${ }^{4}$ Laboratory of Applied Physics, Graduate School of Engineering, Tohoku University, Sendai 980-8579, Japan.

Submitted Jun. 13, 2014; Revised Aug. 17, 2014; Accepted Aug. 29, 2014
}

developing into typical signs of acute leptospirosis, but showing the most common clinical signs instead, such as reproductive failure, precisely, infertility, abortion, premature births and stillbirths. Pig leptospirosis can cause a serious economic loss of pig production and a potential hazard to human health through the direct transmission by the defecation of infected pigs into the outer environment (Kemenes, 1967).

Lipopolysaccharide (LPS) is the major outer membrane component of Leptospira which can affect the virulence of pathogenic Leptospira (Murray et al., 2010). In Leptospira infection, leptospiral lipopolysaccharide (L-LPS) elicits a differential recognition through toll-like receptors (TLRs), such as L-LPS can stimulate immune response via TLR2 and TLR4 in murine cells, while only through TLR2 in human cells (Werts et al., 2001). However, the knowledge of TLRs function in pig innate immunity during Leptospira infection is not clear yet. Our previous study showed that LLPS is capable of inducing the activation of TLR2 rather than TLR4 in pig fibroblasts (PEFs_NCC1), and causing the expression of proinflammatory cytokines (Guo et al., 
2014). The immune response of L-LPS was weak in PEFs_NCC1 cell line; therefore we try to use another pig cell line to elicit pig innate immunity response of L-LPS sufficiently. In the study of Rathi et al. (2010), simian virus 40 (SV40) large $\mathrm{T}$ antigen transfected cell can induce high immune response of mouse embryonic cells. Bases on such study, SV40 large T antigen immortalized pig embryonic fibroblast cell line (PEFs_SV40) has been used to prove TLR2 predominate function in pig innate immunity during Leptospira infection in our experiment.

The L-LPS showed endotoxin-like activity similar to Escherichia coli LPS in the early study (Isogai et al., 1986). After L-LPS stimulation, various proinflammatory cytokines were secreted causing leptospiral uveitis in human (Priya et al., 2008) and liver necrosis in mouse (Isogai et al., 1990). Therefore, the strategies that reduce or prevent the presentation of LPS to its predominate receptors may ease Gram-negative bacteria caused serious disease (De Haas et al., 1999). It has already been reported that antibody against Gram-negative LPS is capable to neutralize endotoxin through inhibiting the interaction between LPS and target cells (Pollack et al., 1997). However the inhibiting effect of antibody against L-LPS on the interaction between L-LPS and pig cells is not understood yet. In this study, antibody against L-LPS has been used to interrupt the interaction between L-LPS and TLR2, instead of the risky antibiotics treatment which might lead to an endotoxin shock.

\section{MATERIALS AND METHODS}

Culture of Leptospira interrogans and preparation of lipopolysaccharide

The LPS from L. interrogans serovar Hebdomadis was extracted by the method of Isogai et al. (1989) as follows. The leptospires were cultured in Ellinghausen-McCulloughJohnson-Harris (EMJH; Difco Laboratories, Detroit, MI, USA) medium with $10 \%$ normal rabbit serum (Gibco, Carlsbad, CA, USA) at $30^{\circ} \mathrm{C}$ for 7 days. The LPS was prepared by the hot phenol-water method and was further purified using a procedure to remove LPS-associated proteins. Escherichia coli serotype O111:B4 LPS (E-LPS) was purchased from Sigma-Aldrich (St. Louis, MO, USA), which was used as a positive control.

Preparation of pig embryonic fibroblast cell line and stimulated with lipopolysaccharide

The pig embryonic fibroblast cell line was immortalized by simian vacuolating virus 40 large $\mathrm{T}$ fragment (PEFs_SV40) as established previously (Fukuda et al., 2012). Cells were cultured in Dulbecco's modified Eagle's medium (DMEM; Nacalai-tesque Inc., Kyoto, Japan) containing $10 \%$ heat-inactivated fetal bovine serum (FBS;
Biowest SAS, Rue de la Caille, Nuaillé, France), $1 \%$ antibiotic and antimycotic solution (Nacalai-tesque). The cells were seeded at $1 \times 10^{6}$ cells/well in 6 well tissue culture plates and cultured at $37^{\circ} \mathrm{C}$ in an incubator with $5 \% \mathrm{CO}_{2}$. Before LPS stimulation, the cells were incubated in an antibiotic-free medium for $2 \mathrm{~h}$. In all experiments, the cell viability was more than $96 \%$, which was evaluated by Trypan blue staining (Invitrogen, Carlsbad, CA, USA). An unstimulated well was prepared as a control in the same cell culture plate. The cell culture supernatants were collected from each well, and adherence cells were harvested using the lysing buffer contained in NucleoSpin RNA II kit (Takara Bio Inc., Shiga, Japan).

RNA extraction, cDNA preparation and real time polymerase chain reaction

Total RNA was isolated from the cells using the NucleoSpin RNA II kit (Takara Bio, Japan) according to manufacturer's protocol, and reverse transcription was performed using PrimeScript RT reagent kit (Takara Bio, Japan). Quantitative real-time polymerase chain reaction (qRT-PCR) reactions were performed on a Thermal Cycler Dice Real-time PCR System II (Takara Bio, Japan) as same procedure as previous experiment (Guo et al., 2014), using SYBR green I mixture (Takara Bio, Japan) and the following primers: swine TLR2 (forward: 5'GCATGAAGATGATGTGGGCC-3', reverse: 5'TAGGAGTCCTGCTCACTGTA-3'), TLR4 (forward: 5'TGGAACAGGTATCCCAGAGG-3', reverse: 5'CAGAATCCTGAGGGAGTGGA-3'), interleukin (IL)-6 (forward: 5'-TGGATAAGCTGCAGTCACAG-3', reverse: 5'-ATTAT CCGAATGGCCCTCAG-3'), IL-8 (forward: 5'GCTCTC TGTGAGGCTGCAGTT-3', reverse: 5'TTTATGCACTGG CATCGAAGTT-3') and swine $\beta$-actin (forward: 5'-CATCACCATCGGCAACGA -3', reverse: 5'GCGTAGAGGTCCTTGCGGATGT-3') serves as an internal control. Each sample was prepared in triplicate and the average value was used as the expression value. Final results were reported as the relative expression level compared with that of non-treatment group after normalization using $\beta$-actin. For visualization, $10 \mu \mathrm{L}$ of the qRT-PCR reaction were subjected to electrophoresis in $10 \%$ Del-gel (Kitasato Medical Service Co., Ltd, Tokyo, Japan) stained with GelRed (Biotium Inc., Hayward, CA, USA). A 100 bp ladder (TrackIt; Invitrogen, Carlsbad, CA, USA) was used as a marker. Pig peripheral blood mononuclear cells (PBMCs) and pig fibroblasts (PEFs_NCC1) which can express of TLR4 mRNA in the previous studies (Uddin et al., 2012; Guo et al., 2014) were used as positive controls.

\section{Enzyme-linked immunosorbent assay}

The protein level of cytokines (IL-6 and IL-8) were measured from PEFs_SV40 cell culture supernatant using 
pig enzyme-linked immunosorbent assay (ELISA) Kits (R\&D Systems Inc., Minneapolis, MN, USA) according to the manufacturer's instructions. The value of the optical density was detected at $450 \mathrm{~nm}$ wavelengths using an ELISA plate reader (BioTek, Winooski, VT, USA) and the concentrations were determined $(\mathrm{pg} / \mathrm{mL})$ with known standards by using Microsoft Excel. To ensure the reproducibility of the experiment, each sample was measured twice and the average concentration was used as protein level $(\mathrm{pg} / \mathrm{mL})$ in cell culture supernatants.

\section{Sodium dodecyl sulfate-polyacrylamide gel} electrophoresis and Western blotting analysis

PEFs_SV40 cells were cultured in 10\% FBS DMEM and stimulated with or without $0.1 \mu \mathrm{g} / \mathrm{mL}$ L-LPS for $3 \mathrm{~h}$ and $72 \mathrm{~h}$. To obtain total protein extract, cells were lysed in solution which containing $50 \mathrm{mM}$ Tris- $\mathrm{HCl}$ (pH 7.4), 0.15 $\mathrm{M} \mathrm{NaCl}, \quad 1 \%$ Triton X-100, $2.5 \mathrm{mg} / \mathrm{mL}$ sodium deoxycholate (Wako Pure Chemical Industries, Osaka, Japan), and a protease inhibitor cock-tail (1:200 dilution, Nacalai-tesque). After calibrating the total protein concentration of cell lysate by a DC Protein assay reagent (Bio-Rad Laboratories, Hercules, CA, USA), $10 \mu \mathrm{g}$ proteins was subjected to SDS-PAGE (ATTO Corporation, Tokyo, Japan) and blotted onto polyvinylidene fluoride membrane (Immobilon-P; Millipore Corporation, MA, USA). The membrane was blotted using the polymer immunocomplexes method as described previously (Fukuda et al., 2000). TLR2 protein expression level was detected with the ECL chemiluminescence Western blot system for immunostaining (GE healthcare, Buckinghamshire, UK). Anti- $\alpha$-tubulin antibody (dilution 1:1,000, Santa Cruz Biotechnology Inc., Santa Cruz, CA, USA) was used as a loading control.

\section{Anti-leptospiral lipopolysaccharide antiserum}

Anti-L-LPS antiserum was prepared from hyperimmunized rabbit as described previously (Isogai et al., 1998). Briefly, one mg of Hebdomadis LPS was emulsified in $1 \mathrm{~mL}$ of complete freund's complete adjuvant. The mixture was injected twice intracutaneously into 10 sites on the shaved back and into the foot of rabbit. Then the rabbit was bled on the 4th post-inoculation week and the serum was used for the experiments. The negative control serum is the preimmune serum (PIS).

\section{Statistical analysis}

All experiments were done in triplicates. Means and standard deviations were calculated from the multiple data. The data were evaluated using Steel's test in Excel software. The values of $\mathrm{p}<0.05\left(^{*}\right)$ and $\mathrm{p}<0.01(* *)$ were considered as statistically significant.

\section{RESULTS}

Expression of toll-like receptor 2 mRNA in PEFs_SV40 cells after leptospiral lipopolysaccharide stimulation

The TLR2 and TLR4 mRNA expressions were analyzed in cultured PEFs_SV40 cells. The TLR4 mRNA with the size of 125 bp expressed in PBMCs and pig fibroblasts (PEFs_NCC1), but not in PEFs_SV40 cells (Figure 1). Thus, the PEFs_SV40 cells which do not express TLR4 mRNA have a potential to be used as a good model in researches on immune response in which TLR2 is involved.

TLR2 mRNA expression in PEFs_SV40 cells was examined while various concentrations of LPSs were applied. Under the stimulation by L-LPS, correspondingly, the expression level of TLR2 mRNA increased gradually while the dose concentration was increasing $(p<0.05)$, the relative values of the expression level in stimulated cells were more than 2.1 folds to that of unstimulated cells (Figure 2A). The E-LPS was used as a positive control, showing drastic and significant increase of expression of TLR2 mRNA from 4 to 25 folds when the doseconcentration range from 0.1 to $10 \mu \mathrm{g} / \mathrm{mL}(\mathrm{p}<0.05$; Figure 2A). We then tested the time-dependent change of TLR2 mRNA expression in PEFs_SV40 cells under $0.1 \mu \mathrm{g} / \mathrm{mL}$ LPSs stimulation. When the cells were incubated with 0.1 $\mu \mathrm{g} / \mathrm{mL}$ L-LPS, the expression of TLR2 mRNA was markedly up-regulated to 2.3 folds at $3 \mathrm{~h}$ and then rapidly declined at $12 \mathrm{~h}$. A significant difference of the expression level between L-LPS stimulated cells and unstimulated cells was maintained until $24 \mathrm{~h}(\mathrm{p}<0.01$; Figure $2 \mathrm{~B})$. When incubated with E-LPS, the maximum expression of TLR2 mRNA was shown at $3 \mathrm{~h}$. After $12 \mathrm{~h}$, the expression level

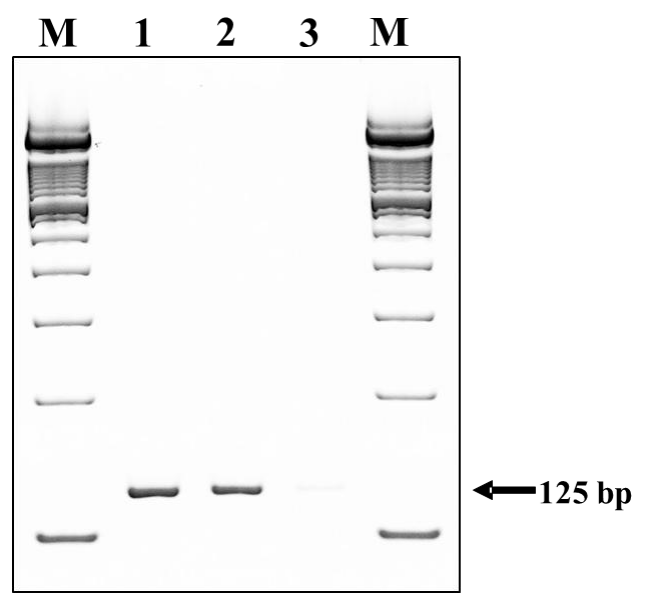

Figure 1. Detection of TLR4 mRNA expression on different kinds of pig cells by qRT-PCR analysis. Lane 1: pig peripheral blood mononuclear cells (PBMCs), lane 2: pig embryonic fibroblast cell line (PEFs_NCC1), lane 3: pig embryonic fibroblast cell line (PEFs_SV40), M: marker (100 bp DNA ladder). TLR4, toll-like receptor 4; qRT-PCR, quantitative real-time polymerase chain reaction. 
was rapidly decreased up to half of the expression level of 3 $\mathrm{h}$ but the expression level was still higher than that of unstimulated cells $(\mathrm{p}<0.05$; Figure $2 \mathrm{~B})$. These results indicate that TLR 2 of pig cells can be activated strongly and quickly after being stimulated by L-LPS.

\section{Expression of toll-like receptor 2 protein in PEFs_SV40} cells after leptospiral lipopolysaccharide stimulation

To examine the protein expression level of TLR2 by the stimulation of L-LPS in the PEFs_SV40 cells, we performed the Western blotting. In unstimulated PEFs_SV40 cells, TLR2 protein with a molecular mass of $74 \mathrm{kDa}$ was stably expressed at low level, and the expression level of TLR2 protein was constant until $72 \mathrm{~h}$ after stimulation (Figure 3). Measurement of brightness of protein band by using Image J software showed that, at $72 \mathrm{~h}$, the expression level of TLR2 protein in L-LPS stimulated cells was about 3.3 folds of that of unstimulated cells. These indicate that TLR2 plays a vital role during L-LPS stimulation, while the protein expression of TLR2 is considerably later than the mRNA transcription (Figure 2B).

\section{Effect of leptospiral lipopolysaccharide stimulation on the production of proinflammatory cytokines}

To understand the inflammatory response triggered by L-LPS, we examined the expression level of cytokines mRNA in the PEFs_SV40 cells by qRT-PCR. The cells were treated with various concentrations of L-LPS, showing significant increase of the mRNA expression of IL-6 $(\mathrm{p}<0.05)$ and IL-8 $(\mathrm{p}<0.05)$ up to more than 30 folds and 40 folds of unstimulated cells, respectively (Figure 4A and B). Also marked enhancement of IL-6 and IL-8 mRNA expression were caused at $3 \mathrm{~h}$ after L-LPS stimulation and then rapidly decreased but the expression level was still higher than that of unstimulated cells $(\mathrm{p}<0.05$; Figure $4 \mathrm{C}$ and D). As a positive control, the cells were treated with ELPS, shows significantly high expression of IL-6 and IL-8 as compared with unstimulated cells $(\mathrm{p}<0.05$; Figure $4 \mathrm{~A}$ and $\mathrm{B}$ ). These expressions were gradually decreased over time (Figure 4C and D).
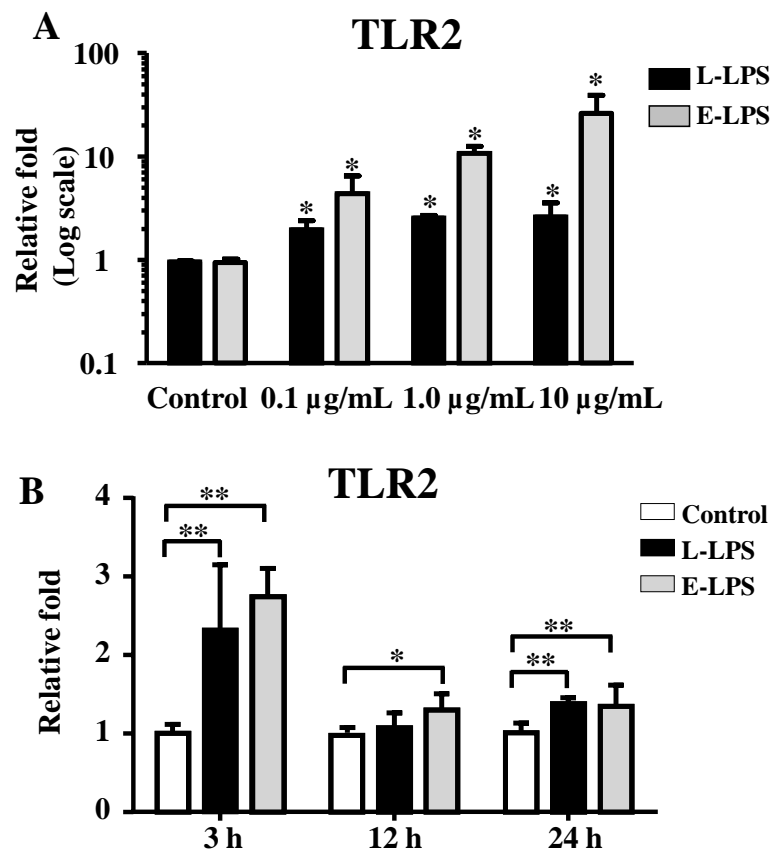

Figure 2. A relative mRNA expression ratio of TLR2 was quantified by qRT-PCR in LPS-induced PEFs_SV40 cells. (A) Cells $\left(1 \times 10^{6}\right.$ cells/well $)$ were isolated after incubation with 0.1 , 1.0 , and $10.0 \mu \mathrm{g} / \mathrm{mL}$ concentrations of LPS at $3 \mathrm{~h}$. (B) Cells were isolated at 3,12, $24 \mathrm{~h}$ after incubation with $0.1 \mu \mathrm{g} / \mathrm{mL}$ LPS. Data shown is an average of $n=3$ biological replicate \pm SD. Levels of expression and significance are relative to unstimulated cells (at each time point for time-dependent experiments). Asterisks indicate significant differences $(* \mathrm{p}<0.05, * * \mathrm{p}<0.01)$. TLR2, tolllike receptor 2; qRT-PCR, quantitative real-time polymerase chain reaction; LPS, lipopolysaccharide; SD, standard deviation.

The amount of IL-6 and IL-8 secreted in culture supernatant were quantitatively determined, showing considerable up-regulation of these cytokines by E-LPS and L-LPS stimulations $(\mathrm{p}<0.05$; Figure 5). In L-LPS stimulations, the secretion level of IL-6 protein was increased until dose of $1.0 \mu \mathrm{g} / \mathrm{mL}$ L-LPS and was slightly decreased at $10 \mu \mathrm{g} / \mathrm{mL}$ L-LPS stimulation (Figure 5A). In contrast, IL-8 secretion was monotonically enhanced with dose concentration of L-LPS (Figure 5B). The secretion

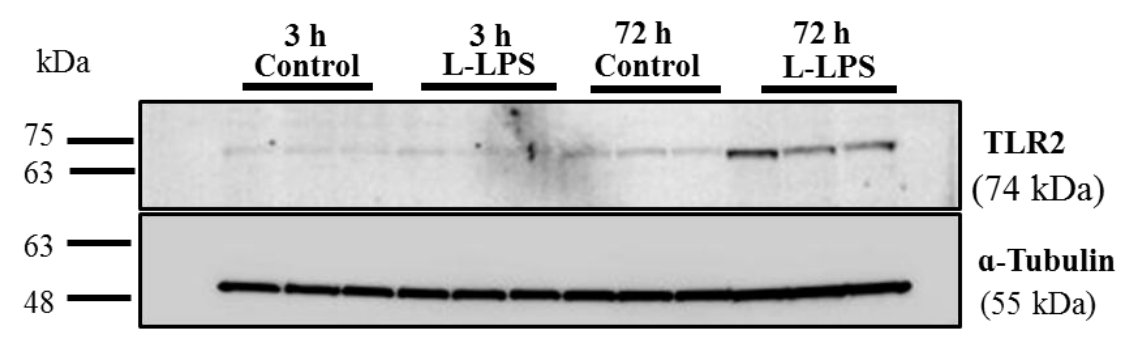

Figure 3. Effect of L-LPS stimulation on expression of TLR2 protein in PEFs_SV40 cells by Western blotting analysis. Cells $\left(1 \times 10^{6}\right.$ cells/well) were stimulated by $0.1 \mu \mathrm{g} / \mathrm{mL}$ L-LPS for $3 \mathrm{~h}$ and $72 \mathrm{~h}$, respectively. Unstimulated cells were used as a control. Three lanes shown in respective experimental conditions are results obtained from triplicated experiments in which cells were separately prepared. The positions of molecular mass markers $(\mathrm{kDa})$ are shown on the left. Anti- $\alpha$-tubulin polyclonal antibody was used to detect $\alpha$-tubulin $(55 \mathrm{kDa})$ as a loading control. L-LPS, leptospiral lipopolysaccharide; TLR2, toll-like receptor 2. 

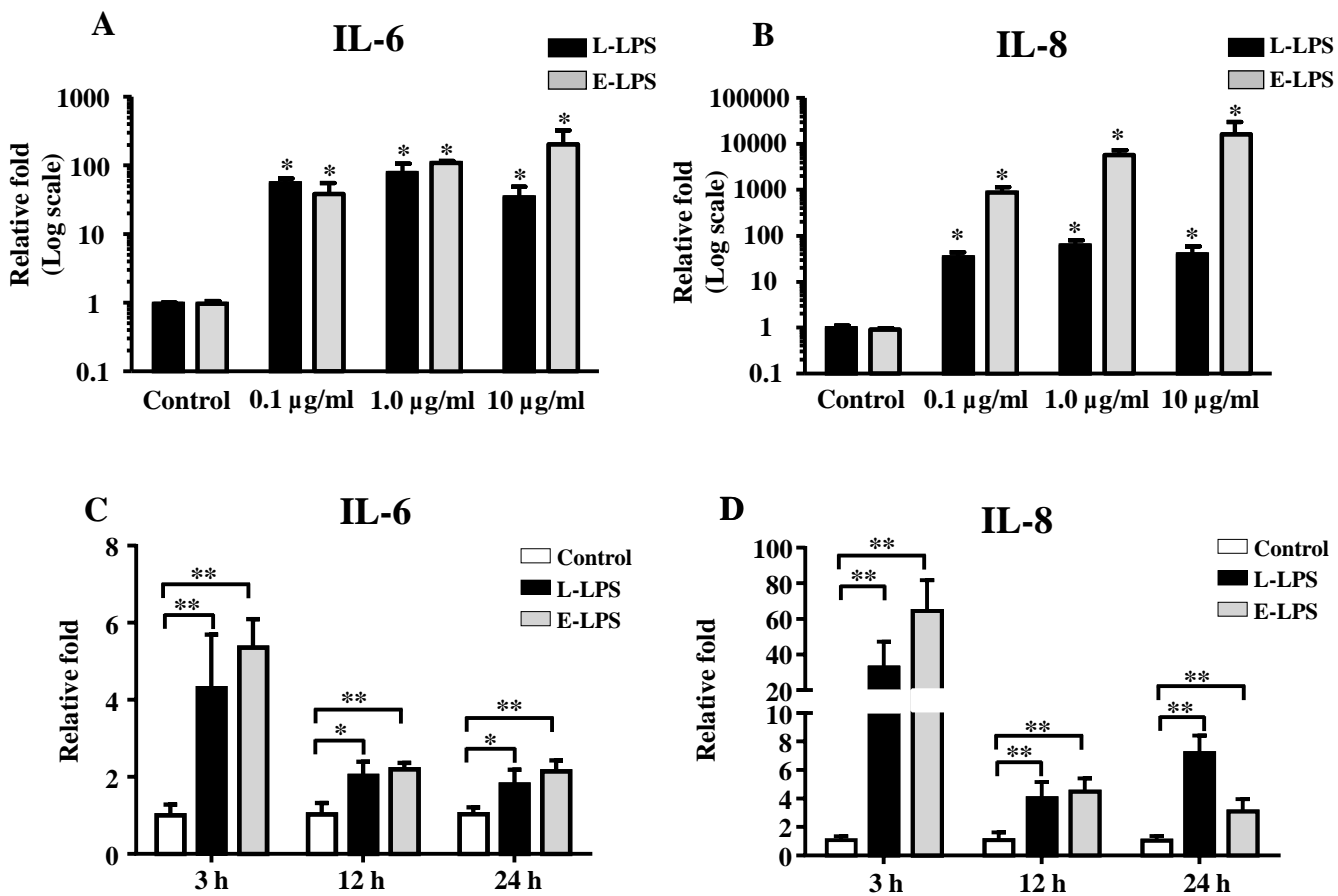

Figure 4. A relative mRNA expression ratio of proinflammatory cytokines were quantified by qRT-PCR in LPS-induced PEFs_SV40 cells. (A) (B) IL-6 and IL-8 mRNA expression in PEFs_SV40 cells after incubation with $0.1,1.0$, and $10.0 \mu \mathrm{g} / \mathrm{mL}$ concentrations of LPS at $3 \mathrm{~h}$. (C) (D) IL-6 and IL-8 mRNA expression in SV40 PEFs after incubation with $0.1 \mu \mathrm{g} / \mathrm{mL}$ LPS at 3, 12, and $24 \mathrm{~h}$. Data shown is an average of $n=3$ biological replicate \pm SD. Levels of expression and significance are relative to unstimulated cells (at each time point for time-dependent experiments). Asterisks indicate significant differences (* $\mathrm{p}<0.05$, ** $\mathrm{p}<0.01)$. qRT-PCR, quantitative real-time polymerase chain reaction; LPS, lipopolysaccharide; IL, interleukin; SD, standard deviation.
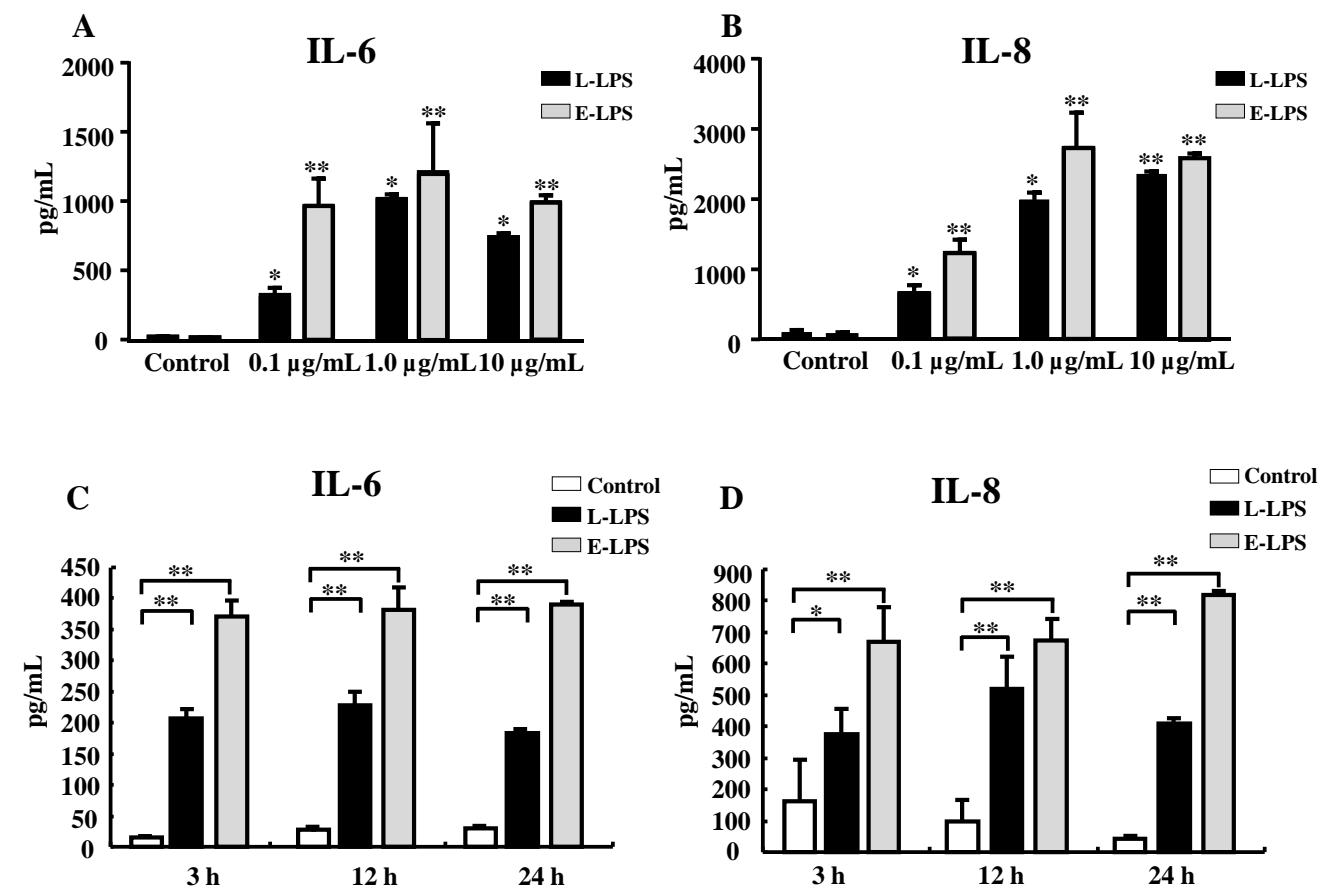

Figure 5. Dose and time-dependent proinflammatory cytokines protein production by LPS-stimulated PEFs_SV40 cells. For dose experiment, cells supernatant fluids were collected at $3 \mathrm{~h}$ after incubation with $0.1,1.0$, and $10.0 \mu \mathrm{g} / \mathrm{mL}$ concentrations of LPS. (A) IL-6, (B) IL-8. For time experiment, cells supernatant fluids were collected at 3, 12, and $24 \mathrm{~h}$ after incubation with concentrations of 0.1 $\mu \mathrm{g} / \mathrm{mL}$ LPS. (C) IL-6, (D) IL-8. Data shown is an average of $\mathrm{n}=3$ biological replicates \pm SD. Asterisks indicate significant differences $(*$ $\mathrm{p}<0.05, * * \mathrm{p}<0.01)$. LPS, lipopolysaccharide; IL, interleukin; SD, standard deviation. 
levels of IL-6 and IL-8 reached the highest level at $3 \mathrm{~h}$ after L-LPS or E-LPS stimulation and retained the level throughout the experiment. Thus, we conclude that L-LPS can rapidly induce production of a large amount of cytokines.

Effects of antibody raises against leptospiral lipopolysaccharide on toll-like receptor 2 expression in PEFs_SV40 cells

When the cells were incubated with both L-LPS (10 $\mu \mathrm{g} / \mathrm{mL}$ ) and anti-L-LPS antibody for $6 \mathrm{~h}$, the enhancement of TLR2 mRNA was completely inhibited by anti-L-LPS antibody comparing with that of L-LPS stimulated cells (Figure 6). While replacing anti-L-LPS antibody by PIS, there was no effect on the TLR2 mRNA expression induced by L-LPS (Figure 6). Altogether, these results indicate that anti-L-LPS can interrupt the interaction between L-LPS and TLR2 in PEFs_SV40 cells, thereafter might reduce the occurrence of antibiotics-triggered endotoxin shock.

\section{DISCUSSION}

In this study, we found that the expression level of TLR2 mRNA increased rapidly even when low concentration of L-LPS was dosed. We also found that a large amount of cytokines, IL-6 and IL-8, were produced relatively soon after L-LPS stimulation. These suggest that the immune response of pig cells could be initiated by

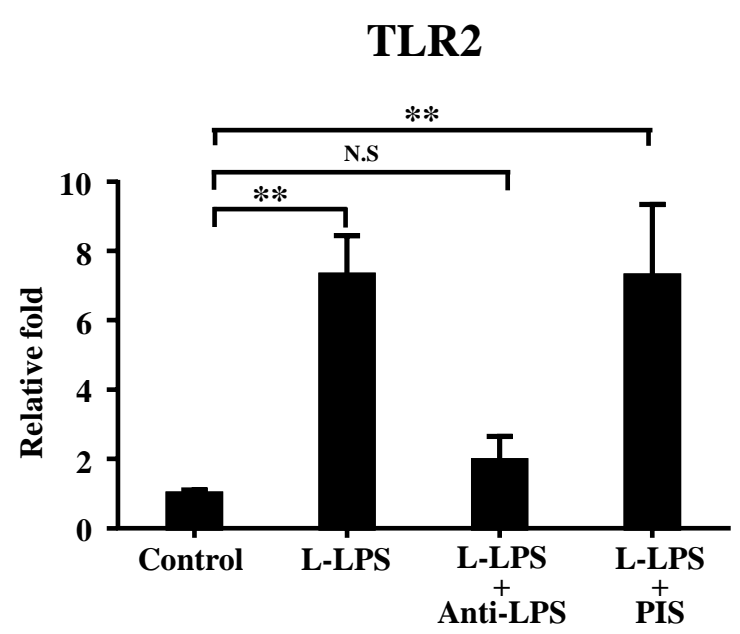

Figure 6. Effects of antibody raised against L-LPS on TLR2 expression in PEFs_SV40 cells. Cells were incubated with 10.0 $\mu \mathrm{g} / \mathrm{mL}$ L-LPS alone or with L-LPS plus an antiserum raised against L-LPS (anti-LPS) or with a preimmune serum (PIS) for 6 h. Statistical analysis was performed between cells stimulated by L-LPS alone or with an antiserum and unstimulated cells. Asterisks indicate significant differences $(* \mathrm{p}<0.05, * * \mathrm{p}<0.01)$. NS means no significant difference between L-LPS plus an antiserum groups and unstimulated one. L-LPS, leptospiral .lipopolysaccharide; TLR2, toll-like receptor 2.
TLR2 but not TLR4. In this view, TLR2 plays a major role to activate the signaling cascade of the immune system in pig cells, ensuring the results obtained in our previous report (Guo et al., 2014). These results were also similar to the research using a human monocyte cell line, which showed the major contribution of TLR2 on the recognition of L-LPS (Werts et al., 2001).

Leptospira infection showed massively high expression of cytokines in infected hamster kidneys (Lowanitchapat et al., 2010). Wagenaar et al. (2009) found that IL-6, IL-8, and IL-1 $\beta$ expression were higher in leptospirosis patients who were associated with severe and fatal disease. These studies indicate that immune response to Leptospira could be the cause of organ damage which has been observed in Leptospira infection (De Fost et al., 2003; Yan et al., 2009). In order to heal the patients with leptospirosis, we commonly use chemotherapy. However, antibiotics treatment would lead Jarisch-Herxheimer reaction, which has been reported to occur which precipitate a febrile inflammatory reaction (Vaughan et al., 1994). In the previous study of treatment to Gram-negative bacteria caused septic shock, antibodies against LPS can be applied to control the immunological response to sepsis, through preventing interaction with LPS binding receptors in target cell (Pollack et al., 1997; De Haas et al., 1999). Here, we found that antibody against L-LPS is capable to inhibit the immune response between Leptospira and TLR2 on pig cells, which shows us a novel vision on prophylaxis of antibiotics-induce endotoxin shock.

In this study, we showed that L-LPS as an immune antigen, triggers the immune response by activating TLR2 during leptospirosis. We also found that the antibody against L-LPS can inhibit the interaction between L-LPS and TLR2 in pig cells, which may impact on immune activation. In addition, the PEFs_SV40 cell line gives us a good model, for the further research on the concern of interaction between pathogenically bacterial antigens and pig TLR2.

\section{ACKNOWLEDGMENTS}

We thank to Mr. Kenichiro Donai (Department of Animal Breeding and Genetics Graduate School of Agriculture, Tohoku University) for kindly review of this manuscript.

\section{REFERENCES}

Brenner, D. J., A. F. Kaufmann, K. R. Sulzer, A. G. Steigerwalt, F. C. Rogers, and R. S. Weyant. 1999. Further determination of DNA relatedness between serogroups and serovars in the family Leptospiraceae with a proposal for Leptospira alexanderi sp. nov. and four new Leptospira genomospecies. Int. J. Syst. Bacteriol. 49: 839-858. 
Cerqueira, G. M. and M. Picardeau. 2009. A century of Leptospira strain typing. Infect. Genet. Evol. 9: 760-768.

De Fost, M., R. A. Hartskeerl, M. R.Groenendijk, and T. van der Poll. 2003. Interleukin 12 in part regulates gamma interferon release inhuman whole blood stimulated with Leptospira interrogans. Clin. Diagn. Lab. Immunol. 10:332-335.

De Haas, C. J. C., R. van der Zee, B. Benaissa-Trouw, K. P. M. van Kessel, J. Verhoef, and J. A. G. van Strijp. 1999. Lipopolysaccharide (LPS)-binding synthetic peptides derived from serum amyloid P component neutralize LPS. Infect. Immun. 67:2790-2796.

Faine, S. 1994. Leptospira and leptospirosis. CRC Press, Boca Raton, FL, USA.

Fukuda, T., M. Katayama, T. Yoshizawa, T. Eitsuka, H. Mizukami, K. Nakagawa, H. Ito, H. Komagata, S. H. Song, S. Roh, Y. Hoshino, E. Sato, H. Hanada, K. Nishimori, T. Miyazawa, and T. Uchida. 2012. Efficient establishment of pig embryonic fibroblast cell lines with conditional expression of the simian vacuolating virus 40 large $\mathrm{T}$ fragment. Biosci. Biotechnol. Biochem. 76:1372-1377.

Fukuda, T., Y. Tani, T. Kobayashi, Y. Hirayama, and O. Hino. 2000. A new western blotting method using polymer immunocomplexes: detection of Tsc1 and Tsc2 expression in various cultured cell lines. Anal. Biochem. 285:274-276.

Guo, Y., T. Fukuda, K. Donai, K. Kuroda, M. Masuda, S. Nakamura, H. Yoneyama, and E. Isogai. 2014. Leptospiral lipopolysaccharide stimulates the expression of toll-like receptor 2 and cytokines in pig fibroblasts. Anim. Sci. J. (In press).

Isogai, E., H. Isogai, T. Kubota, N. Fujii, S. Hayashi, T. Indoh, S. Takagi, H. Miura, and K. Kimura. 1998. Apoptosis of lymphocytes in mice dministered lipopolysaccharide from Leptospira interrogans. J. Vet. Med. B. 45:529-537.

Isogai, E., H. Isogai, N. Fujii, and K. Oguma. 1990. Macrophage activation by leptospiral lipopolysaccharide. Zentralbl. Bakteriol. 273:200-208.

Isogai, E., H. Isogai, Y. Kurebayashi, and N. Ito. 1986. Biological activities of leptospiral lipopolysaccharide. Zentralbl. Bakteriol. Mikrobiol. Hyg. A 261:53-64.

Isogai, E., H. Kitagawa, H. Isogai, T. Matsuzawa, T. Shimizu, Y. Yanagihara, and K. Katami. 1989. Effects of leptospiral lipopolysaccharide on rabbit platelets. Zentralbl. Bakteriol. 271:186-196.

Kemenes, F. 1967. Leptospirosis of the swine. Monatsh Veterinarmed. 22: 224-233.
Lowanitchapat, A., S. Payungporn, A. Sereemaspun, P. Ekpo, D. Phulsuksombati, Y. Poovorawan, and C. Chirathaworn. 2010. Expression of TNF-alpha, TGF-beta, IP-10 and IL-10 mRNA in kidneys of hamsters infected with pathogenic Leptospira. Comp. Immunol. Microbiol. Infect. Dis. 33:423-434.

Murray, G. L., A. Srikram, R. Henry, R. A. Hartskeerl, R. W. Sermswan, and B. Adler. 2010. Mutations affecting Leptospira interrogans lipopolysaccharide attenuate virulence. Mol. Microbiol. 78:701-709.

Pollack, M., C. A. Ohl, D. T. Colenbock, F. Di Padova, L. M. Wahl, N. L. Koles, G. Guelde, and B. G. Monkst. 1997. Dual effects of LPS antibodies on cellular uptake of LPS and LPS-induced proinflammatory functions. J. Immunol. 159:3519-3530.

Priya, C. G., S. R. Rathinam, and V. Muthukkaruppan. 2008. Evidence for endotoxin as a causative factor for leptospiral uveitis in humans. Invest. Ophthalmol. Vis. Sci. 49:5419-5424.

Rathi, A. V., P. G. Cantalupo, S. N. Sarkar, and J. M. Pipas. 2010. Induction of interferon-stimulated genes by simian virus $40 \mathrm{~T}$ antigens. Virology 406:202-211.

Uddin, M. J., P. K. Nuro-Gyina, M. A. Islam, D. Tesfaye, E. Tholen, C. Looft, K. Schellander, and M. U. Cinar. 2012. Expression dynamics of Toll-like receptors mRNA and cytokines in porcine peripheral blood mononuclear cells stimulated by bacterial lipopolysaccharide. Vet. Immunol. Immunopathol. 147:211-222.

Vaughan, C., C. C. Cronin, E. K. Walsh, and M. Whelton. 1994. The Jarisch-Herxheimer reaction in leptospirosis. Postgrad. Med. J. 70:118-121.

Wagenaar, J. F., M. H. Gasem, M. G. Goris, M. Leeflang, R. A. Hartskeerl, T. van der Poll, C. van 't Veer, and E. C. van Gorp. 2009. Soluble ST2 levels are associated with bleeding in patients with severe leptospirosis. PLoS. Negl. Trop. Dis. 3(6): e453.

Werts, C., R. I. Tapping, J. C. Mathison, T. H. Chuang, V. Kravchenko, I. S. Girons, D. A. Haake, P. J. Godowski, F. Hayashi, A. Ozinsky, D. M. Underhill, C. J. Kirschning, H. Wagner, A. Aderem, P. S. Tobias, and R. J. Ulevitch. 2001. Leptospiral lipopolysaccharide activates cells through a TLR2dependent mechanism. Nat. Immunol. 2:346-352.

Yan, W., S. M. Faisal, S. P. McDonough, T. J. Divers, S. C. Barr, C. F. Chang, M. J. Pan, and Y. F. Chang. 2009. Immunogenicity andprotective efficacy of recombinant Leptospira immunoglobulin- like protein B ( $\mathrm{rLigB})$ in a hamster challenge model. Microbes Infect. 11:230-237. 